Published in final edited form as:

Biochemistry. 2006 February 7; 45(5): 1383-1392. doi:10.1021/bi0518242.

\title{
Effects of a distal mutation on active site chemistry ${ }^{\dagger}$
}

\author{
Lin Wang ${ }^{\S}$, Scott Tharp§, Tzvia Selzer ${ }^{\ddagger},{ }^{\wedge}$, Stephen J. Benkovic ${ }^{\ddagger}$, and Amnon Kohen $§,{ }^{*}$ \\ $\S$ Department of Chemistry, University of Iowa, Iowa City, IA 52242 \\ $\$$ Department of Chemistry, The Pennsylvania State University, University Park, Pennsylvania 16802
}

\begin{abstract}
Previous studies of E. coli dihydrofolate reductase (ecDHFR) have demonstrated that residue G121, which is $19 \AA$ away from the catalytic center, is involved in catalysis and long distance dynamical motions were implied. Specifically, the ecDHFR mutant G121V has been extensively studied by various experimental and theoretical tools, and the mutation's effect on kinetic, structural, and dynamical features of the enzyme explored. The current work examined the effect of this mutation on the physical nature of the catalyzed hydride transfer step by means of intrinsic kinetic isotope effects (KIEs), their temperature dependence and activation parameters as described before for the wild type ecDHFR (Sikorski et al. 2004, J. Am. Chem. Soc., 126, 4778-4779). The temperature dependence of initial velocities was used to estimate activation parameters. Isotope effects on the preexponential Arrhenius factors, and the activation energy could be rationalized by an environmentally coupled hydrogen tunneling model, similar to the one used for the wild type enzyme. Yet, in contrast to the wild type, fluctuations of the donor-acceptor distance were now required. Secondary $\left(2^{\circ}\right)$ KIEs were also measured for both $\mathrm{H}$ and D transfer and, as in the case of the wild type enzyme, no coupled motion was detected. Despite these similarities, the reduced rates, the slightly inflated $1^{\circ}$ KIEs and their temperature dependence, together with relatively deflated $2^{\circ}$ KIEs, indicate that the potential surface prearrangement was not as ideal as for the wild type enzyme. These findings support theoretical studies suggesting that the G121V mutation lead to a different conformational ensemble of reactive states and less effective rearrangement of the potential surface, but has only small effect on H-tunneling.
\end{abstract}

Dihydrofolate reductase from Escherichia coli (ecDHFR) is a small monomeric enzyme (18 $\mathrm{kDa}$ ) that consists of eight-stranded $\beta$-sheet and four $\alpha$-helices connected with several loop regions. It catalyzes the reduction of 7,8-dihydrofolate (DHF) to 5,6,7,8-tetrahydrofolate (THF) with the concomitant oxidation of NADPH (nicotinamide adenine dinucleotide phosphate, reduced form) to $\mathrm{NADP}^{+}$, in which a hydride is stereospecifically transferred from the pro- $R \mathrm{C} 4$ position of the nicotinamide ring to the si face of the C6 position of pterin. This enzyme helps maintain intracellular pools of THF used in the biosynthesis of purine nucleotides and some amino acids. Furthermore the essential role of DHFR in DNA synthesis and in a variety of anabolic pathways makes it a common target for antiproliferative therapeutics. Due to its biological and pharmacological importance, and it being a small monomeric enzyme, DHFR has been the subject of intensive structural and kinetic investigation over many years, serving as a paradigm of enzymatic systems in many experimental and theoretical studies (1$8)$.

\footnotetext{
${ }^{\dagger}$ This work was supported by NIH R01 GM65368-01 and NSF CHE- 0133117 to A.K.

* Corresponding author: Amnon Kohen, Department of Chemistry, University of Iowa, Iowa City, IA 52242, Tel: 319-335-0234. Fax: 319-335-1270. Email: amnon-kohen@uiowa.edu.

${ }^{\wedge}$ Current address: Department of structural Biology, The Weizmann Institute of Science, Rehovot Israel
} 
The complete kinetic scheme for wild type ecDHFR was derived from equilibrium binding, steady-state, and pre-steady-state kinetic experiments $(9,10)$. That kinetic scheme revealed that the entire kinetic cascade is rather complex, and that the slowest step at neutral $\mathrm{pH}$ is THF release, while the hydride transfer step (the chemical step) is mostly rate-limiting at $\mathrm{pH}$ over 8.0. Similar kinetic schemes were constructed for mutant enzymes, laying down the foundation for studies of relationships between kinetics and mutations (11-20). In addition to kinetic studies, structural studies suggested that residues 9-24, denoted as the Met-20 loop, adopt three different conformations (closed, occluded, and open) during the catalytic cycle, and that these conformations are stabilized by interactions between the Met-20 loop and the $\beta \mathrm{F}-\beta \mathrm{G}$ loop (residues 117-131) (21).

Two-dimensional heteronuclear $(1 \mathrm{H}-15 \mathrm{~N})$ nuclear magnetic relaxation studies of DHFR demonstrated that glycine-121, though $19 \AA$ away from the catalytic center of the enzyme, had large-amplitude backbone motions on the nanosecond time scale (22-24). Equilibrium binding studies of G121V-ecDHFR indicated that the mutant retained wild-type binding properties with respect to dihydrofolate and tetrahydrofolate; however, binding to NADPH and $\mathrm{NADP}^{+}$was decreased by 40-fold and 2-fold, respectively, relative to wild-type DHFR (23). In yet another study of G121V-ecDHFR that is relevant to this paper, adiabatic compressibility that was determined by the sound velocity indicated a modified volume fluctuation of the native state (25). These results emphasized the role of G121 in packing and stability affecting the enzyme function, via long-range interactions $(26,27)$. Finally, CD and fluorescence spectroscopy studies indicated that the folding pattern of the enzyme was also altered by G121V mutation (6), which is in accordance with substantial effect of G121V on the protein thermal dynamics.

Support for the connection between enzyme dynamics and catalysis in DHFR came from various theoretical studies. Very different simulations and molecular dynamic studies suggested strong correlated and anticorrelated side chain motions involving spatially removed residues, including G121 (3-5,28). A computational study by Thorpe \& Brooks III (29) suggested that DFT and NADPH populate preferentially a region of configurational space of DHFR that is conducive to the reaction, while substrate and cofactor become trapped in unproductive configurations in G121V-ecDHFR. Hybrid quantum-classical molecular dynamics simulations done by Hammes-Schiffer and coworkers $(3,5)$ indicated that the decrease in the hydride transfer rate for G121V-DHFR was due to an increase in the free energy barrier but not to a decrease in the transmission coefficients, suggesting that this mutation may interrupt the network of motions coupled to the H-transfer. According to these studies mutations spatially removed from the active site caused nonlocal structural perturbations and significantly affected the catalysis by altering the conformational motions of the entire protein.

These, and other studies, suggested that the G121V mutant affects the dynamic, kinetic and folding properties of the enzyme. This mutant is probably the mutant of ecDHFR that has been studied most intensively. The goal of the present work is to check whether and how this mutation affects the chemical step (C-H-C hydride transfer) of the DHFR catalyzed reaction, and its coupling to the protein dynamics.

Previous studies of G121V that attempted to better isolate the H-transfer from other kinetic steps used stopped-flow methods $(11,30)$. These pre-steady-state experiments at $\mathrm{pH} 7$ indicated that the rate of hydride transfer was reduced from 220 (for wild type) to $1.3 \mathrm{~s}^{-1}$. The kinetic analysis was complicated by a conformational change, which preceded $\mathrm{H}$-transfer and occurred at a rate of $3.5 \mathrm{~s}^{-1}$. If this step exists in the kinetic mechanism of the wild-type enzyme, then it would be predicted to occur at a rate higher than $2000 \mathrm{~s}^{-1}$. In order to test the suggested dynamic coupling between a remote residue to the H-transfer step at the active site, the effect of the mutation on the H-transfer step has to be isolated from other kinetic steps. Then, effects 
on the coupling between the active site environment and the nature of the $\mathrm{H}$-transfer have to be compared to these of the wild type enzyme.

While studying the wild type $e c$ DHFR, we have demonstrated that intrinsic KIE can be extracted from competitive KIE experiments of $1^{\circ} \mathrm{H} / \mathrm{T}$ and D/T KIE and that these KIEs appeared to expose the nature of the chemical step better than most other methods (31). The temperature dependence of the intrinsic KIEs indicated possible contributions of quantum mechanical hydrogen tunneling and enzyme motion to the wild type enzyme catalysis. Additionally, $2^{\circ}$ KIEs were used to test possible coupling between the $1^{\circ}$ and $2^{\circ}$ hydrogens on the donor carbon (4C of NADPH). The present study used the same kinetic tools to investigate the effect of G121V on the nature of the hydride transfer step. A comparison of the findings to the wild type enzyme isolated effects of the mutation on the H-transfer event from its effects on other kinetic steps. This in turn, afforded direct comparison to relevant theoretical studies, which most generally focus on that step.

\section{MATERIALS AND METHODS}

\section{Materials}

All materials were obtained from Sigma unless otherwise indicated. 7,8-Dihydrofolate (DHF) was prepared by dithionite reduction of folic acid as described by Blakely $(32) \cdot\left[1-{ }^{2} \mathrm{H}\right]$-glucose available from Sigma came with $\sim 98 \%$ deuterium content, which is insufficient for use in competitive KIE measurements. $\left[1{ }^{2} \mathrm{H}\right]$-glucose was prepared by reduction of $\delta-$ gluconolactone with $5 \%$ sodium mercury amalgam in $99.96 \%$ deuterium oxide $\left(\mathrm{D}_{2} \mathrm{O}\right)(33)$. The $\mathrm{C} 1$ deuterium content of the product was over $99.9 \%$ as determined by ${ }^{1} \mathrm{H}-\mathrm{NMR}$.

Synthesis of labeled cofactors for $1^{\circ} \mathrm{KIEs}-\boldsymbol{R}\left[\mathbf{4}^{-2} \mathrm{H}\right]-\mathrm{NADPH}$ was prepared through stereospecific reduction of $\mathrm{NADP}^{+}$with 2-propanol- $\mathrm{d}_{8}(>99.7 \% \mathrm{D}$ at $2 \mathrm{C}$ as determined by $\left.{ }^{1} \mathrm{H}-\mathrm{NMR}\right)$ using alcohol dehydrogenase from Thermoanaerobium brockii (tbADH) (34, 35). $\boldsymbol{R}\left[\mathbf{4}^{-}{ }^{3} \mathbf{H}\right]-\mathbf{N A D P H}(680 \mathrm{mCi} / \mathrm{mmol})$ was synthesized by reduction of $\mathrm{NADP}^{+}$using glucose dehydrogenase from Cryptococcus uniguttulatus (GluDH), followed by oxidation of the resulting NADPH with acetone using $t b \mathrm{ADH}$, followed by a second reduction with unlabeled glucose using GluDH as described in more details elsewhere (36). [Ad- ${ }^{\mathbf{1 4}} \mathbf{C}$ ]NADPH $(50 \mathrm{mCi} / \mathrm{mmol})$ was prepared by 2 -phosphorylation of $\left[\mathrm{Ad}^{-1}{ }^{14} \mathrm{C}\right]-\mathrm{NAD}^{+}$using an $\mathrm{NAD}^{+}$kinase from chicken liver to produce $\left[\mathrm{Ad}_{-}{ }^{14} \mathrm{C}\right]-\mathrm{NADP}^{+}$, followed by reduction with glucose using GluDH as described elsewhere (37). $\boldsymbol{R}\left[\mathbf{4}, \mathbf{4}^{\mathbf{2}} \mathbf{H},{ }^{\mathbf{3}} \mathbf{H}\right]-\mathbf{N A D P H}(680 \mathrm{mCi} / \mathrm{mmol})$ was prepared by following a three-step procedure: $\mathrm{NADP}^{+}$was reduced to $S\left[4-{ }^{3} \mathrm{H}\right]-\mathrm{NADPH}$ with $\left[1-{ }^{3} \mathrm{H}\right]$-glucose using GluDH, oxidized by acetone using $t b \mathrm{ADH}$, and finally the resulting $\left[{ }^{3}{ }^{3} \mathrm{H}\right]-\mathrm{NADP}^{+}$was reduced with $\left[1-{ }^{2} \mathrm{H}\right]-$ glucose using GluDH. Prior to the final reduction, tbADH was removed by ultrafiltration. $\left[\mathbf{A d}-{ }^{14} \mathbf{C}, \mathbf{4}^{2} \mathbf{H}_{\mathbf{2}}\right]-\mathbf{N A D P H}(50 \mathrm{mCi} / \mathrm{mmol})$ was prepared from $\left[\mathrm{Ad}_{-}{ }^{14} \mathrm{C}\right]-\mathrm{NADP}^{+}$, which was synthesized as described above, and then reduced with $\left[1-{ }^{2} \mathrm{H}\right]$-glucose to produce $4 S\left[\mathrm{Ad}-{ }^{14} \mathrm{C}, 4-{ }^{2} \mathrm{H}\right]-\mathrm{NADPH}$ using GluDH. $4 S\left[\mathrm{Ad}-{ }^{14} \mathrm{C}, 4^{-2} \mathrm{H}\right]-$ NADPH was then oxidized with acetone to produce $\left[\mathrm{Ad}-{ }^{14} \mathrm{C}, 4-{ }^{2} \mathrm{H}\right]-\mathrm{NADP}^{+}$using $t b \mathrm{ADH}$, following by a second reduction with $\left[1-{ }^{2} \mathrm{H}\right]$-glucose.

Synthesis of labeled cofactors for $2^{\circ} \mathrm{KIEs}-S$ [4- $\left.{ }^{3} \mathrm{H}\right]-\mathrm{NADPH}$ was prepared by reduction of $\mathrm{NADP}^{+}$with $\left[1{ }^{-} \mathrm{H}\right]$-glucose using GluDH. $\boldsymbol{R}\left[\mathbf{A d}^{-14} \mathbf{C}, \mathbf{4}^{-2} \mathbf{H}\right]-\mathbf{N A D P H}$ was prepared by reduction of $\left[\mathrm{Ad}_{-}{ }^{14} \mathrm{C}\right]-\mathrm{NADP}^{+}(37)$ with $\left[1-{ }^{2} \mathrm{H}\right]$-glucose using GluDH. $\boldsymbol{S}$ $\left[4,4-{ }^{3} \mathbf{H},{ }^{2} \mathbf{H}\right]-\mathbf{N A D P H}$ was prepared by reduction of NADP ${ }^{+}$with $\left[1-{ }^{2} \mathrm{H}\right]$-glucose using GluDH, followed by oxidation with acetone using $t b \mathrm{ADH}$ and second reduction with $\left[1-{ }^{3} \mathrm{H}\right]-$ glucose using GluDH. Prior to the final reduction $t b \mathrm{ADH}$ was removed by ultrafiltration.

A mixture of $S\left[4-{ }^{3} \mathrm{H}\right]-\mathrm{NADPH}$ with $\left[\mathrm{Ad}-{ }^{14} \mathrm{C}\right]-\mathrm{NADPH}$ for $2^{\circ} \mathrm{H} / \mathrm{T}$ KIE measurements with $\mathrm{H}$-transfer was prepared by reducing $\left[\mathrm{Ad}^{-14}{ }^{14} \mathrm{C}\right]-\mathrm{NADP}^{+}$with $\left[1-{ }^{3} \mathrm{H}\right]$-glucose using GluDH. A 
mixture of $S\left[4,4-{ }^{3} \mathrm{H},{ }^{2} \mathrm{H}\right]-\mathrm{NADPH}$ with $R$ [Ad- $\left.{ }^{14} \mathrm{C}, 4-{ }^{2} \mathrm{H}\right]-\mathrm{NADPH}$ for $2^{\circ} \mathrm{H} / \mathrm{T}$ KIE measurements with D-transfer was prepared by reduction of a mixture of $\left[4{ }^{3} \mathrm{H}\right]-\mathrm{NADP}^{+}$and $\left[\mathrm{Ad}^{14}{ }^{14} \mathrm{C}\right]-\mathrm{NADP}^{+}(36,37)$ with $\left[\mathrm{U}^{2} \mathrm{H}\right]$-isopropanol $\left(>99.3 \% \mathrm{D}\right.$ in $2 \mathrm{C}$ as determined by ${ }^{1} \mathrm{H}-$ NMR) using $t b \mathrm{ADH}$.

All synthesized cofactors were purified by semipreparative reverse-phase HPLC on a Supelco Discovery C18 column $(25 \mathrm{~cm} \times 10 \mathrm{~mm}, 5 \mu \mathrm{l})$ as described before (38) and lyophilized for long-term storage at $-80{ }^{\circ} \mathrm{C}$.

Enzyme preparation-The G121V mutant of Escherichia coli DHFR (G121V-ecDHFR), was expressed, purified and stored as discussed elsewhere $(11,30)$.

\section{Methods}

\section{Preparation of samples for competitive KIE experiments-For $1^{\circ} \mathrm{KIE}$} measurements, [Ad- $\left.{ }^{14} \mathrm{C}\right]-\mathrm{NADPH}$ and $R\left[4{ }^{3} \mathrm{H}\right]-\mathrm{NADPH}$ (H/T experiments) or $\left[\mathrm{Ad}-{ }^{14} \mathrm{C}\right.$, $\left.4^{2}{ }^{2} \mathrm{H}_{2}\right]-\mathrm{NADPH}$ and $R\left[4,4-{ }^{2} \mathrm{H},{ }^{3} \mathrm{H}\right]-\mathrm{NADPH}$ (D/T experiments) were combined in radioactivity ratio close to $1: 6\left({ }^{14} \mathrm{C} /{ }^{3} \mathrm{H}\right.$, compensating for the lower efficiency of tritium scintillation counting). Each of the mixtures was copurified by reverse-phase HPLC on a Supelco Discovery C18 column $(25 \mathrm{~cm} \times 4.6 \mathrm{~mm}, 5 \mu \mathrm{l})$, divided into aliquots containing $300,000 \mathrm{dpm}$ of ${ }^{14} \mathrm{C}$ and frozen in liquid nitrogen for short-term storage ( $<3$ weeks) at $-80^{\circ}$ C.

For $2{ }^{\circ} \mathrm{H} / \mathrm{T}$ KIE measurements, mixtures of [Ad- $\left.{ }^{14} \mathrm{C}\right]-\mathrm{NADPH}$ and $S\left[4-{ }^{3} \mathrm{H}\right]-\mathrm{NADPH}$ or $R$ [Ad- $\left.-{ }^{14} \mathrm{C}, 4-{ }^{2} \mathrm{H}\right]-\mathrm{NADPH}$ and $S\left[4,4-{ }^{3} \mathrm{H},{ }^{2} \mathrm{H}\right]$-for experiments with $\mathrm{H}$ or $\mathrm{D}$ transfer, respectively, were repurified by HPLC, divided into $300,000 \mathrm{dpm}{ }^{14} \mathrm{C}$ aliquots (sufficient for ten HPLC injections) and stored at $-80{ }^{\circ} \mathrm{C}$ for less than three weeks.

Competitive kinetic isotope effects (KIE)—All experiments were performed in MTEN (50mM 2-morpholinoethanesulfonic acid, $25 \mathrm{mM}$ Tris, $25 \mathrm{mM}$ ethanolamine, and $100 \mathrm{mM}$ $\mathrm{NaCl})$ at $\mathrm{pH} 8.0$ under an atmosphere of oxygen over a range of $5-45^{\circ} \mathrm{C}$. In each experiment, one aliquot of the copurified labeled NADPH was thawed just before use. DHF was added to the reaction mixture to a final concentration of $0.85 \mathrm{mM}$, (approximately 200 fold excess over the $4 \mu \mathrm{M}$ NADPH). The final volume was brought to $1040 \mu \mathrm{l}$ by adding MTEN and the $\mathrm{pH}$ was readjusted to 8.0 at the experimental temperature. Oxygen was bubbled through the reaction mixture for $5 \mathrm{~min}$ to ensure the trapping of the product (THF). Before initiating the reaction, two $100 \mu \mathrm{l}$ samples $(t=0)$ were withdrawn. Two other $100 \mu \mathrm{l}$ aliquots for infinite time samples $(\mathrm{t}=\infty)$ were also removed and w.t. ecDHFR (approx. 0.2 unit) was added to each of the latter two samples to ascertain complete fractional conversion. The reaction was initiated by adding G121V-DHFR. At various time points $100 \mu \mathrm{l}$ aliquots were withdrawn at fractional conversions (f) ranging from $25 \%$ to $85 \%$ as determined from the ${ }^{14} \mathrm{C}$ distribution between NADPH and $\mathrm{NADP}^{+}$. All samples were quenched with methotrexate (final conc. $1.8 \mathrm{mM}$ ). The overall reaction ran between $15-40 \mathrm{~min}$. and all quenched samples were immediately frozen and stored in dry ice.

Prior to HPLC-LSC analysis, the samples were thawed and bubbled with oxygen for 3 minutes. The samples were then injected into reverse phase HPLC for separation of the reactants and products using the analytical method described elsewhere (38). Fractions $(0.8 \mathrm{ml})$ were collected every minute, mixed with $10 \mathrm{ml}$ Ultima Gold liquid scintillation cocktail (PerkinElmer) and stored in the dark for over 24 hours before $\beta$-emission analysis with a Packard Tricarb Tr2900 liquid scintillation counter (LSC) for $5 \mathrm{~min} / \mathrm{sample}$. Infinite time samples $(t=\infty)$ were processed identically as the time points to estimate background levels of radiation and the ratios of ${ }^{3} \mathrm{H} /{ }^{14} \mathrm{C}$ at $\mathrm{t}=\infty\left(\mathrm{R}_{\infty}\right)$. Blank samples $(\mathrm{t}=0)$ were used to assure the 
quality and purity of the label NADPHs. The observed KIEs were calculated according to (39):

$$
\mathrm{KIE}=\frac{\ln (1-f)}{\ln \left[1-f \cdot\left(\mathrm{R}_{\mathrm{t}} / \mathrm{R}_{\infty}\right)\right]}
$$

where the fractional conversion $(f)$ was determined from the ratio of ${ }^{14} \mathrm{C}$ in product to the total ${ }^{14} \mathrm{C}$, which was calculated from:

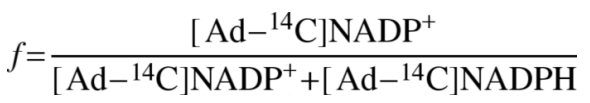

and $\mathrm{R}_{\mathrm{f}}$ and $\mathrm{R}_{\infty}$ are ratios of ${ }^{3} \mathrm{H} /{ }^{14} \mathrm{C}$ in products at various fractional conversions and at $100 \%$ conversion, respectively. Each experiment resulted in at least 5 time points and was performed at least in duplicate.

Intrinsic KIEs-The intrinsic D/T KIEs were derived by numerically solving the following equation (40-44):

$$
\frac{\mathrm{T}_{(V / K)_{\mathrm{D}, \mathrm{obs}}^{-1}-1}^{\mathrm{T}}(V / K)_{\mathrm{H}, \mathrm{obs}}^{-1}-1}{\left.\mathrm{~T}_{\mathrm{D}} / k_{\mathrm{T}}\right)^{-3.34}-1}
$$

where ${ }^{\mathrm{T}}(V / K)_{\mathrm{H}, \text { obs }}$ and ${ }^{\mathrm{T}}(V / K)_{\mathrm{D} \text {,obs }}$ are the observed $\mathrm{H} / \mathrm{T}$ and $\mathrm{D} / \mathrm{T}$ KIEs, respectively, and $k_{\mathrm{D}} /$ $k_{\mathrm{T}}$ is the intrinsic D/T KIE. The intrinsic H/T KIE is formulated as $\left(k_{\mathrm{D}} / k_{\mathrm{T}}\right)(41,45)$. In the procedure it is assumed that the Swain-Schaad relationship holds or have little temperature dependence for intrinsic primary KIEs $(41,44,46)$. In systems where non-classical isotope effects have been suggested from temperature dependency or theoretical simulation, the experimental relationship between $1^{\circ} \mathrm{H} / \mathrm{T}$ and D/T KIEs have been shown to be very close to the semiclassical limit (44,47-50). Several recent gas phase calculations for small model reaction also result in Swain-Schaad exponent that at ambient temperature $\left(300-350{ }^{\circ} \mathrm{K}\right) \mathrm{did}$ not deviate significantly from its semiclassical value (51-55). Furthermore, even if the magnitude of the exponent (3.3) was altered for a full tunneling model, it would not be expected to change over the narrow temperature range under study and, hence, wouldn't affect the trend manifested in the temperature dependence of the intrinsic isotope effects $(31,46)$. To eliminate other common assumptions associated with this procedure (44), the overall reaction should be irreversible in the procedure. Accordingly, the experiments were designed to ensure the irreversibility of the overall reaction by trapping the product THF with oxygen (38). Values for intrinsic H/T and H/D KIEs were calculated numerically using the appropriate modification of Equation 3 (44). Standard errors on the intrinsic KIEs were calculated by calculating the intrinsic KIEs from the raw data (without averaging procedure) followed by standard error analysis as described by Francisco et al. (46), Sikorski et al. (31), and in more details in the Supplementary Information.

The isotope effects on the activation parameters for the intrinsic KIEs were calculated by fitting them to the Arrhenius equation for KIEs:

$$
k_{\mathrm{L}} / k_{\mathrm{I}}=\left(A_{\mathrm{L}} / A_{\mathrm{I}}\right) \mathrm{e}^{\Delta \mathrm{Ea}_{\mathrm{I}-\mathrm{L}} / \mathrm{RT}}
$$

where $\mathrm{L}$ represents $\mathrm{H}$ or $\mathrm{D}$ and $\mathrm{I}$ represents $\mathrm{D}$ or $\mathrm{T} . \mathrm{A}_{\mathrm{L}} / \mathrm{A}_{\mathrm{I}}$ and $\Delta \mathrm{Ea}_{\mathrm{I}-\mathrm{L}}$ are the isotope effect on the preexponential Arrhenius factors and the difference in activation energy between $\mathrm{L}$ and I respectively.

'Equation 3 cannot be solved analytically. Ref. (44) offer a table (its Appendix 1) that offers numerically calculated values for a range of observed KIEs for this kind of equations. More recently, we posted on our web site a free of charge, JAVA script based, program that can numerically solve Equation 1 for any experiment of interest (URL: cricket.chem.uiowa.edu/kohen/tools.html). 
Non-competitive KIEs-Initial velocity measurements were obtained under saturating conditions of both the substrate and cofactor $(100 \mu \mathrm{M})$ by monitoring the decrease in $340 \mathrm{~nm}$ absorbance $\left(\Delta \varepsilon_{340}=13.2 \mathrm{mM}^{-1} \mathrm{~cm}^{-1}\right)(56)$. Experiments were carried out over a temperature range of $5-45^{\circ} \mathrm{C}$ using a Hewlett-Packard 8453 series UV/Vis spectrophotometer equipped with a water-jacketed cuvette holder. All assays were performed in MTEN buffer ( $\mathrm{pH}$ 8.0, adjasted at the experimental temperature) containing $1 \mathrm{mM}$ DTT. In a typical experiment, $30 \mu \mathrm{l} 100 \mathrm{nM}$ enzyme was pre-incubated with $100 \mu \mathrm{M}$ cofactor, and the reaction initiated by addition of $100 \mu \mathrm{M}$ substrate. DHF and NADPH saturation was ensured by doubling the concentrations of DHF and NADPH at the temperature extremes, which did not affect the measured rates. Turnover rates were also determined with $100 \mu \mathrm{M} R\left[4,4-{ }^{1} \mathrm{H},{ }^{2} \mathrm{H}\right]-\mathrm{NADPH}$ using the same procedure. All measurements were performed at least in triplicate and standard deviations for each temperature set were computed. Calculated $k_{\text {cat }}$ values for each temperature were fit to the Arrhenius equation using a non-linear least-squares regression, in which errors were weighted using the standard deviations. The resulting parameters were used to calculate the activation parameters, and the noncompetitive KIEs on $k_{\text {cat }}$.

\section{RESULTS AND DISCUSSION}

\section{Competitive $1^{\circ} \mathrm{KIEs}$}

Mixed labeling experiments were conducted with G121V-ecDHFR using the same method previously used to study the wild type ecDHFR (31). Primary H/T and D/T V/K KIE measurements were conducted as described briefly in Ref (31) and in more details here (Materials and Methods). As for the wild type enzyme, the intrinsic H/D, H/T and D/T KIEs were calculated numerically from the observed $\mathrm{H} / \mathrm{T}$ and D/T KIEs through the methodology developed by Northrop $(40,44,57)$. The average intrinsic KIEs and their respective standard errors were then used in calculating the isotope effects on the activation parameters. Tables summarizing the observed and intrinsic $1^{\circ} \mathrm{H} / \mathrm{T}$ and $\mathrm{D} / \mathrm{T}$ isotope effects over a temperature range from $5^{\circ} \mathrm{C}$ to $45^{\circ} \mathrm{C}$ are given in the Supplementary Information. Figure 1 presents the observed (open structures) and intrinsic (close structures) KIEs for both wild type (panel a) (31) and G121V (panel b) ecDHFRs. Figure 2 presents only the intrinsic H/T KIEs for the wild type (blue) and G121V (red) to better asses the differences between these two enzymes. The same trend is also observed for the H/D and D/T KIEs. Apparently, all the KIEs of G121V are slightly larger than those measured with wild-type DHFR and are slightly temperature dependent.

The reason that the observed KIEs are often smaller than their corresponding intrinsic KIEs is that isotopically insensitive kinetic steps "mask" the intrinsic KIEs. In the current work the KIEs were measured under irreversible reaction conditions and the kinetic complexity can be formulated as follows $(44,58)$ :

$$
{ }^{\mathrm{T}}(\mathrm{V} / \mathrm{K})_{\mathrm{L}, \mathrm{obs}}=\frac{\mathrm{k}_{\mathrm{L}} / \mathrm{k}_{\mathrm{l}}+\mathrm{C}_{\mathrm{f}}}{1+\mathrm{C}_{\mathrm{f}}}
$$

where $\mathrm{C}_{\mathrm{f}}$ represents the forward commitment to catalysis, which is the ratio of the forward isotopically insensitive step over preceding reverse steps. The intrinsic $\mathrm{H} / \mathrm{D} \mathrm{KIE}$ at $25^{\circ} \mathrm{C}$ afforded calculations of the commitment on the pre-steady-state hydride transfer rate at the same temperature and $\mathrm{pH} 7$ as reported in Ref. (11). The KIE measured for G121V by presteady-state kinetics using UV absorbance and fluorescence resonance energy transfer (FRET) at $25^{\circ} \mathrm{C}$ was 2.4 (30). The intrinsic KIE that we report here is $4.9 \pm 0.2$, suggesting a commitment close to 1.8 on the pre-steady-state KIEs. In accordance with Ref s. (30) and (31), a model that may explain the commitment on the pre-steady-state hydride transfer rate includes two kinetic steps, the isotopically insensitive flip of the nicotinamide ring out of the active site (the reverse of flip-in observed by FRET (30)), and the hydride transfer itself. Taken together, the much 
slower flip-in of the nicotinamide ring $\left(3.5 \mathrm{~s}^{-1}\right.$ and $2000 \mathrm{~s}^{-1}$ for G121V-DHFR and w.t. $e c$ DHFR, respectively) and the increased pre-steady-state commitment for the G121V-DHFR suggest that the flip-out is also slower for the mutant. Similar conclusions were reached by Wright et al. from their NMR studies $(23,59)$, identifying the effect of the G121V mutation on the rates and thermodynamic distribution of the different conformational ensembles of the same wild type and mutant enzymes studied here (24). According to Wright's experiments, the motion of the nicotinamide ring seems to be correlated to the motion of the M20 loop from occluded to closed conformation. It is important to note that the protein-substrate coherent motion, suggested from the NMR studies, is not an indication of protein modes coupled to the $\mathrm{H}$-transfer coordinate, which is the focus of the current work. The coupled motion identified by Wright and coworkers $(24,59)$ is involved in the orientation of the reactants in the active site prior to the chemical step (H-transfer). Such motion might be relevant to the formation of near attack conformation (NAC) as suggested by Bruice and co-workers (60-62), but is part of the commitment and not the chemical step. As emphasized in the following section, the current work examine the effect of the dynamically altered mutant G121V on the C-H-C transfer step, which is the only step in which covalent bonds are cleaved or made (cf., the chemical step). $\bullet$

\section{Temperature dependence of intrinsic KIEs and rates}

The measured H/T and D/T KIEs were used to calculate the intrinsic KIEs. Figure 1 presents Arrhenius plots (KIE on a logarithmic scale vs. the reciprocal of the absolute temperature) for the observed and intrinsic KIEs for both wild type (reproduced from Ref. (31)) and G121V mutant (from this study, see Tables in the Supplementary Information). While the intrinsic KIEs for the wild type enzyme appeared temperature independent, those of G121V were a little larger and some temperature dependency is apparent (Figure 2). The temperature dependence was further examined by fitting the intrinsic KIEs to Eq. 4 (the lines in Figure 1 and 2) and the fitting parameters are summarized in Table 1.

Initial velocity studies between 20 to $45^{\circ} \mathrm{C}(\mathrm{pH}=9$, at which chemistry is more rate limiting on $k_{\text {cat }}$ for both enzymes $\left.(9,11)\right)$ resulted in similar activation energies for both enzymes $\left(E_{a}\right.$ $=3.7 \pm 0.2$ and $3.2 \pm 0.3 \mathrm{kcal} / \mathrm{mol}$ for wild type and G121V, respectively). Below $20^{\circ} \mathrm{C} E_{a}$ for both enzymes was larger indicating a change in rate limiting step. These $E_{a} \mathrm{~s}$ are in accordance with a pre-steady-state study (for the chemical step) and steady state (for product release step) measurements by Maglia and Alemann (63). Naturally, $\Delta H^{\dagger}$ s for both enzymes (above $20^{\circ} \mathrm{C}$ ) were also similar $\left(\Delta \Delta H^{*}=0.5 \pm 0.5 \mathrm{kcal} / \mathrm{mol}\right)$. Apparently, the difference in rates between the two enzymes results from $\mathrm{T} \Delta \Delta S^{\ddagger}=3.5 \pm 0.8 \mathrm{kcal} / \mathrm{mol}$ at $297 \mathrm{~K}$ (Table 1 ).

The initial velocities were also measured with $R$ [4- $\left.{ }^{2} \mathrm{H}\right]-\mathrm{NADPH}$ (under the same conditions), and the resulting KIEs on $k_{\text {cat }}$ were all temperature independent and within the range of 2.8 \pm 0.6 . This value is similar (within experimental errors) to the one measured by pre-steady-state experiments, supporting the conclusion of Cameron et al. (11) that at $\mathrm{pH} 8$ the same kinetic steps limited $k_{\mathrm{cat}}$ and $k_{\mathrm{H} \text {-transfer }}$. As discussed below, this provides additional support to the suggested interpretation.

This paper focuses on the effect of the distal mutation on the chemical step, so effects on the intrinsic KIEs are discussed in detail. As apparent from Table 1, all isotope effects on the Arrhenius preexponential factors lie well above the semiclassical limits $(39,57,64-67)$. Traditionally, using a tunneling correction to transition state theory $(39,64)$, such phenomenon would be interpreted as an indication for tunneling of both heavy and light isotopes (68). Yet, the relatively small size of the KIEs and the measured energy of activation cannot be explained

•For the purpose of this work hydrogen-bonds are not considered covalent bonds. 
by such a tunneling correction, which predict very large KIEs and no energy of activation at the regime where both isotopes tunnel, leading to temperature independent KIEs $(68,69)$. "Marcus like" models (discussed in the following section) appear to explain the findings better. These models can also be used to rationalize the lack of isotope effects on the activation energy for the wild type enzyme and the small, but non-zero $E_{a}$ for the mutant (Table 1).

\section{“Marcus Like” models (Environmentally Coupled Tunneling)}

Models assuming 1-dimensional rigid potential surface successfully reproduced temperature independent large KIEs with no activation energy of the isotopically sensitive step (48). For temperature independent small KIEs with a significant activation energy a different kind of model is required. The Markus theory of electron and proton transfer in condensed phase offered a relevant procedure (70-73). Several phenomenological models were developed in recent years that fall under the title "Marcus like" models (e.g., Refs (74-80)). All these models were constructed assuming that rates and KIEs can be measured for a single kinetic step (the chemical step), and thus are relevant to the experimental efforts described here. Although these different models were constructed from very different basic principles, they all share several mathematical and physical aspects. Mathematically, they separate the temperature dependence of the reaction rate from that of the KIEs. This enables rationalization of systems with or without temperature dependent KIEs whether the barrier for the reaction is significant or not. From the physical point of view, all these models suggest that (i) the hydrogen should be treated quantum mechanically throughout the reaction coordinate (including tunneling); (ii) fluctuations of the reaction's potential surface are at a time scale similar or slower than the H-transfer rate, and thus determine the overall rates (81) (the solvent coordinate is the reaction coordinated as stated by Kiefer and Hynes $(51,52)$; and (iii) these fluctuations can be treated as two orthogonal vibrations, one that represents fluctuations of the donor-acceptor distance and second that represents changes in the system's symmetry (Figure 3). Various terms have been coined recently to characterize $\mathrm{H}$-transfer in enzymatic systems, including "vibrationally enhanced tunneling" (79), "rate-promoting vibrations" (80) and "environmentally coupled tunneling" (74,75). In this paper we use the term "Environmentally Coupled Tunneling" (ECT) that was coined by Knapp and Klinman (74), although other terms coined by others are as valid. This model follows the treatment of Kuznetsov and Ulstrup (82), and the changes in the system's symmetry are addressed as system "rearrangement" (the "Marcus" term) and fluctuations of the donor-acceptor distance as "gating" (the "Franck-Condon" term). The first term (represented by the $p$ coordinate in Figure 3 ) is not dependent on the mass of the transferred particle (no KIE) but determine most of the energy of activation of the rate. The second term (represented by the $q$ coordinate in Figure 3) determines the KIEs and their temperature dependence (e.g., no "gating", no temperature dependence on the KIEs).

According to this interpretation the lack of temperature dependence of the KIEs and the large $A_{\mathrm{l}} / A_{\mathrm{h}}$ for the wild type $e c$ DHFR are rationalized as a perfect "rearrangement" (the $\boldsymbol{p}$ coordinate in Figure 3) of the potential surface, so that the average donor-acceptor distance is right for tunneling and no "gating" (fluctuations along the $\boldsymbol{q}$ coordinate, Figure 3 ) is needed. For the G121V mutant on the other hand, the slightly inflated KIEs and their small, but non-zero, temperature dependence, would indicate that the "rearrangement" is not perfect, and that the average donor-acceptor distance is larger than for the wild type enzyme. Accordingly, some thermally activated "gating" is required which leads to the slight temperature dependence of the KIEs. Additionally, this model is also in accordance with the slightly inflated KIEs as $\mathrm{H}$ tunnels from longer distance than D. $\cdots$

“. Franck-Condon integral for $\mathrm{H}$ is significant at larger distances than that of D (74). 
An alternative to the phenomenological models would be QM/MM studies such as these described in Refs (2), (83), and (84). While studying ecDHFR for example, Garcia-Viloca et al. (7) predicted a $2^{\circ} \mathrm{KIE}$ (which is a sensitive probe of the reaction's potential surface and was later confirmed experimentally (31)); Pu et al. (8) could reproduce the trends of temperature dependence for $1^{\circ} \mathrm{KIEs}$, and Agarwal et al. (28) could reproduce and predict several experimental data. All these studies could address the role of protein motion and other mechanistic features that are not directly accessible by experimental studies. Since the substantial features of "Marcus like" models are embedded in the QM/MM simulation, it would be worthwhile to "extract" features like "gating" from such simulations. Such efforts by Hammes-Shiffer and co-workers while studying the enzyme lipoxygenase (85) and by Warshel and co-workers while studying alcohol dehydrogenase (86) resulted in very interesting insights.

Interestingly, the isotope effect on the preexponential Arrhenius factors for the wild type and mutant enzymes are practically the same (within experimental errors). This in turn, suggests that despite the 163 fold difference in rates $(11,30)$, the mutation has not substantially altered the nature of the hydride transfer. This conclusion is also in agreement with MM/QM calculations by Hammes-Shiffer and co-workers $(1,28)$ that suggested a similar nature of $\mathrm{H}$ transfer $(\kappa)$ but larger free energy barrier $\left(\Delta G^{\ddagger}\right)$. Interestingly, the effects of the mutation on the activation parameters $\left(\mathrm{T} \Delta S^{\ddagger}=3 \pm 1 \mathrm{kcal} / \mathrm{mole}\right.$ at $300 \mathrm{~K}$ and $\Delta H^{\ddagger}=0.5 \pm 1.7 \mathrm{kcal} / \mathrm{mol}$ ), suggest that most of the difference between the wild type and G121V is entropic and not on the enthalpy of activation. A deconvolution of the free energy of activation calculated from the simulation reported in Ref. (28) into entropic and enthalpic components might be able to give insight to these findings.

Wright and co-workers compared the conformational ensembles of the reactant and product states of both wild type and G121V ecDHFRs $(23,24)$. They concluded that the "close" conformation of loop M20 (believed to be the productive one) is more prevalent in the reactant state of the wild type enzyme. Taken together with the present kinetic findings, it is ttempting to suggest that their findings can now be extended beyond these two stable states to indicate different conformational ensembles at the transition state. Yet, this extension is only circumstantial, because the spectroscopic data examined two stable states while the kinetic data are also affected by the transition state and thus reflect its nature.

The hybrid quantum-classical molecular dynamic simulation conducted by Watney et al. (5) also suggested that the conformational ensemble at the transition state is affected by the G121V mutation. That simulation compared the wild type enzyme to the G121V mutant and the results suggested that the mutation affected both the conformational ensembles of the mutant along the reaction coordinate and the coupling of its dynamics to the H-transfer event. Furthermore, the calculations indicated that most of the effect of the mutation on the enzyme's activity was by altering the potential surface reorganization, and only small change in the degree of tunneling and the transmission coefficient was observed. The findings presented here provide experimental support to both conclusions. Apparently, the nature of the H-transfer was not altered significantly, and less perfect reorganization is in accordance with the slightly inflated KIEs and their temperature dependence.

Finally, $2^{\circ} \mathrm{H} / \mathrm{T}$ KIEs for the G121V mutant $\left(\right.$ at $25{ }^{\circ} \mathrm{C}$ ) were measured with $S\left[4-{ }^{3} \mathrm{H}\right]$-and with $S\left[4,4-{ }^{3} \mathrm{H},{ }^{2} \mathrm{H}\right]-\mathrm{NADPH}$, namely with $\mathrm{H}$ - and D-transfer from the $1^{\circ} \mathrm{I}$ position. The observed $2^{\circ}$ KIEs were $1.087 \pm 0.005$ and $1.125 \pm 0.007$, for $\mathrm{H}$ - and $\mathrm{D}$-transfer, respectively. The observed $2^{\circ} \mathrm{KIE}$ and the commitments for $\mathrm{H}$ and $\mathrm{D}$ reported above $\left(\mathrm{C}_{\mathrm{f}}\right.$ of $0.7 \pm 0.1$ and $0.15 \pm 0.05$ for $\mathrm{H}$ - and D-transfer, respectively) were used to calculate the intrinsic KIEs (Eq. 5). These intrinsic $2^{\circ} \mathrm{KIEs}$ were identical within experimental errors $(1.15 \pm 0.01$ and $1.14 \pm 0.02$ for $\mathrm{H}$ and D-transfer, respectively). As in the case of the wild type enzyme (31), no breakdown of the rule of geometrical mean (87) was apparent, providing no evidence for $1^{\circ}-2^{\circ}$ coupled 
motion $(57,67,88-90)$. These intrinsic $2^{\circ} \mathrm{H} / \mathrm{T}$ KIEs are smaller than these measured for the wild type enzyme $1.19 \pm 0.2(31)$, suggesting different transition state conformations, and possibly different carbon center rehybridization. The lack of coupled motion for both enzymes agrees with a similar nature of the $\mathrm{H}$-transfer mechanism, but reduced $2^{\circ} \mathrm{KIEs}$ indicate some differences in the system's vibrational states, which could be in agreement with different rearrangements of the potential surface close to the transition state. Interestingly, a more rigorous MM/QM study of the $2^{\circ} \mathrm{KIEs}$ for the wild type ecDHFR indicated non-synchronized hybridization of the donor and acceptor carbons and slightly associative transition state (91). A similar study of the G121V mutant is under way, and it's findings may shed light on the differences between the transition state ensembles of the wild type and G121V ecDHFRs.

\section{CONCLUSIONS}

The H-transfer step in the reaction catalyzed by the mutant G121V-ecDHFR was examined and compared to that of the wild type ecDHFR. The temperature dependence of the intrinsic $1^{\circ}$ KIEs with G121V yields isotope effects on Arrhenius parameters that lie well above the semiclassical limits, and were identical (within experimental errors) to the wild type enzyme. The enthalpy of activation for both enzymes at high $\mathrm{pH}$ (where the chemical step is more rate limiting for both enzymes) was also similar, and most of the rate differences appear associated with change in entropy. The findings with both the wild type ecDHFR (31) and G121V$e c$ DHFR are consistent with environmentally coupled hydrogen tunneling (74) and other "Marcus like" models in which the motion of the active site is coupled to the H-transfer coordinate. The G121V mutation seems to have little effect on the nature of H-transfer, yet, while the wild type $e c$ DHFR reaction presented no temperature dependence of the KIEs, that of the mutant did indicate small, but non-zero, temperature dependence of these KIEs. Several phenomenological working-models can be used to rationalize our current findings. Using the terminology coined the Knapp and Klinman model, the wild type reaction involves environmentally coupled $\mathrm{H}$-tunneling with perfect pre-organization of the potential surface (no donor-acceptor gating motion needed). Alternatively, the models such as Truhlar (81) or of Kiefer and Hynes $(51,52)$ would suggest that for the wild type enzyme the rearrangement of the "solvent coordinate" leads to an average distance of donor and acceptor that is ideal for tunneling. The G121V mutation ( $19 \AA$ Arom the reaction center) seems to affect the preorganization of the system so that some thermally activated donor-acceptor fluctuations now affect $\mathrm{H}$-tunneling, resulting in slightly larger and more temperature dependent KIEs. These findings are in accordance with this remote residue being part of a dynamic network that is coupled to the catalyzed chemistry $(1,3,5,7,30)$. These $\mathrm{QM} / \mathrm{MM}$ models did not deconvolute their simulation in terms used by the "Marcus like" models mentioned above. Consequently, direct comparison of simulation and phenomenological studies is yet to come.

The $2^{\circ} \mathrm{H} / \mathrm{T}$ KIEs measured with either $\mathrm{H}$ - or D-transfer were identical (within experimental errors). This result does not indicate coupled motion between the $1^{\circ}$ and $2^{\circ} \mathrm{C} 4$ hydrogens $(68,69)$. A similar conclusion has been drawn for the wild type enzyme from the "mixed labeling" experiment (in which $2^{\circ} \mathrm{H} / \mathrm{T}$ is measured with $\mathrm{H}$-transfer and $2^{\circ} \mathrm{D} / \mathrm{T}$ with D-transfer $(67,88,92)$. The comparison of the two enzymes is again in accordance with similar nature of $\mathrm{H}$-transfer. The size of the $2^{\circ} \mathrm{KIEs}$ on the other hand was smaller for the G121V indicating differences in transition state structure and vibrational states. A QM/MM study, similar to the one conducted with the wild type (91), is under way to explore the differences in these $2^{\circ}$ KIEs on the molecular level.

In the future tools similar to those described above will be used to examine the effect of dynamic perturbation of DHFR on its catalyzed chemistry. Different theoretical studies suggested that other residues (specifically, M42 and S148) also participate in the same network of protein motions as G121, and that this network is directly coupled to the H-transfer event $(1-3,29)$. Of 
special interest are the mutants M42W and M42W-G121V, for which non-additive decrease in rates suggested synergism between residues 121 and 42 (30). Recent study (3) suggested that several other residues, and specifically S148, were also part of the same network. Detailed examination of different combinations of the G121V-M42W-S148A single, double and triple mutants, using the tools described above, is yet to be conducted.

\title{
Supplementary Material
}

Refer to Web version on PubMed Central for supplementary material.

\section{Acknowledgements}

The authors are grateful to Majd Haddad for technical assistance.

\author{
Abbreviations \\ DHFR \\ dihydrofolate reductase \\ KIE \\ kinetic isotope effect \\ RP HPLC \\ Reverse Phase High Pressure Liquid Chromatography \\ LSC \\ Liquid Scintillation Counter \\ DHF \\ 7,8-dihydrofolate \\ THF \\ 5,6,7,8-tetrahydrofolate \\ TEAA \\ triethyl ammonium acetate \\ NADPH \\ nicotinamide adenine dinucleotide 2'-phosphate (reduced form) \\ NADP $^{+}$ \\ nicotinamide adenine dinucleotide 2 '-phosphate (oxidized form)

\section{References} \\ 1. Agarwal PK, Billeter SR, Rajagopalan PTR, Benkovic SJ, Hammes-Schiffer S. Network of coupled \\ promoting motions in enzyme catalysis. Proc Natl Acad Sci USA 2002;99:2794-2799. [PubMed: \\ 11867722] \\ 2. Benkovic SJ, Hammes-Schiffer S. A perspective on enzyme catalysis. Science 2003;301:1196-1202. \\ [PubMed: 12947189] and many cited therein \\ 3. Wong KF, Selzer T, Benkovic SJ, Hammes-Schiffer S. Chemical theory and computation special \\ feature: impact of distal mutations on the network of coupled motions correlated to hydride transfer \\ in dihydrofolate reductase. Proc Natl Acad Sci USA 2005;102:6807-6812. [PubMed: 15811945] \\ 4. Rod TH, Radkiewicz JL, Brooks CL. Correlated motion and the effect of distal mutations in \\ dihydrofolate reductase. Proc Natl Acad Sci USA 2003;100:6980-6985. [PubMed: 12756296]
}


5. Watney JB, Agarwal PK, Hammes-Schiffer S. Effect of mutation on enzyme motion in dihydrofolate reductase. J Am Chem Soc 2003;125:3745-3750. [PubMed: 12656604]

6. Swanwick RS, Shrimpton PJ, Allemann RK. Pivotal role of Gly 121 in dihydrofolate reductase from Escherichia coli: the altered structure of a mutant enzyme may form the basis of Its diminished catalytic performance. Biochemistry 2004;43:4119-4127. [PubMed: 15065854]

7. Garcia-Viloca M, Truhlar DG, Gao J. Reaction-path energetics and kinetics of the hydride transfer reaction catalyzed by dihydrofolate reductase. Biochemistry 2003;42:13558-13575. [PubMed: 14622003]

8. Pu J, Ma S, Gao J, Truhlar DG. Small temperature dependence of the kinetic isotope effect for the hydride transfer reaction catalyzed by Escherichia coli dihydrofolate reductase. J Phys Chem 2005;19:8551-8556.

9. Fierke CA, Johnson KA, Benkovic SJ. Construction and evaluation of the kinetic scheme associated with dihydrofolate reductase from Escherichia coli. Biochemistry 1987;26:4085-4092. [PubMed: 3307916]

10. Miller GP, Benkovic SJ. Stretching exercises--flexibility in dihydrofolate reductase catalysis. Chemistry \& biology 1998;5:R105-113. [PubMed: 9578637]

11. Cameron CE, Benkovic SJ. Evidence for a functional fole of the dynamics of glycine-121 of Escherichia coli dihydrofolate reductase obtained from kinetic analysis of a site-directed mutant. Biochemistry 1997;36:15792-15800. [PubMed: 9398309]

12. Miller GP, Wahnon DC, Benkovic SJ. Interloop contacts modulate ligand cycling during catalysis by Escherichia coli dihydrofolate reductase. Biochemistry 2001;40:867-875. [PubMed: 11170407]

13. Miller GP, Benkovic SJ. Strength of an interloop hydrogen bond determines the kinetic pathway in catalysis by Escherichia coli dihydrofolate reductase. Biochemistry 1998;37:6336-6342. [PubMed: 9572848]

14. Adams JA, Fierke CA, Benkovic SJ. The function of amino acid residues contacting the nicotinamide ring of NADPH in dihydrofolate reductase from Escherichia coli. Biochemistry 1991;30:1104611054. [PubMed: 1834173]

15. Fierke CA, Benkovic SJ. Probing the functional role of threonine-113 of Escherichia coli dihydrofolate reductase for its effect on turnover efficiency, catalysis, and binding. Biochemistry 1989;28:478-486. [PubMed: 2496745]

16. Benkovic SJ, Fierke CA, Naylor AM. Insights into enzyme function from studies on mutants of dihydrofolate reductase. Science 1988;239:1105-1110. [PubMed: 3125607]

17. Mayer RJ, Chen JT, Taira K, Fierke CA, Benkovic SJ. Importance of a hydrophobic residue in binding and catalysis by dihydrofolate reductase. Proc Nat Acad Sci USA 1986;83:7718-7720. [PubMed: 3463995]

18. Wagner CR, Huang Z, Singleton SF, Benkovic SJ. Molecular basis for nonadditive mutational effects in Escherichia coli dihydrofolate reductase. Biochemistry 1995;34:15671-15680. [PubMed: 7495797]

19. Huang Z, Wagner CR, Benkovic SJ. Nonadditivity of mutational effects at the folate binding site of Escherichia coli dihydrofolate reductase. Biochemistry 1994;33:11576-11585. [PubMed: 7918371]

20. Li L, Falzone CJ, Wright PE, Benkovic SJ. Functional role of a mobile loop of Escherichia coli dihydrofolate reductase in transition-state stabilization. Biochemistry 1991;31:7826-7833. [PubMed: 1510968]

21. Sawaya MR, Kraut J. Loop and subdomain movements in the mechanism of Escherichia coli dihydrofolate reductase: crystallographic evidence. Biochemistry 1997;36:586-603. [PubMed: 9012674]

22. Epstein DM, Benkovic SJ, Wright PE. Dynamics of the dihydrofolate reductase-folate complex: catalytic sites and regions known to undergo conformational change exhibit diverse dynamical features. Biochemistry 1995;34:11037-11048. [PubMed: 7669761]

23. Osborne MJ, Schnell J, Benkovic SJ, Dyson HJ, Wright PE. Backbone dynamics in dihydrofolate reductase complexes: Role of loop flexibility in the catalytic mechanism. Biochemistry 2001;40:9846-9859. [PubMed: 11502178] 
24. McElheny D, Schnell JR, Lansing JC, Dyson HJ, Wright PE. Defining the role of active-site loop fluctuations in dihydrofolate reductase catalysis. Proc Nat Acad Sci USA 2005;102:5032-5037. [PubMed: 15795383]

25. Gekko K, Tamura Y, Ohmae E, Hayashi H, Kagamiyama H, Ueno H. A large compressibility change of protein induced by a single amino acid substitution. Protein Science 1996;5:542-545. [PubMed: 8868493]

26. Gekko K, Kunori Y, Takeuchi H, Ichihara S, Kodama M. Point mutations at glycine-121 of Escherichia coli dihydrofolate reductase: important roles of a flexible loop in the stability and function. Journal of Biochemistry (Tokyo, Japan) 1994;116:34-41.

27. Gekko K, Ohmae E. Analysis of loop function of dihydrofolate reductase. Seibutsu Butsuri 2004;44:70-74.

28. Agarwal PK, Billeter SR, Hammes-Schiffer S. Nuclear quantum effects and enzyme dynamics in dihydrofolate reductasecatalysis. J Phys Chem B 2002;106:3283-3293.

29. Thorpe IF, Brooks CL III. The coupling of structural fluctuations to hydride transfer in dihydrofolate reductase. Proteins 2004;57:444-457. [PubMed: 15382243]

30. Rajagopalan PTR, Stefan L, Benkovic SJ. Coupling interactions of distal residues enhance dihydrofolate reductase catalysis: Mutational effects on hydride transfer rates. Biochemistry 2002;41:12618-12628. [PubMed: 12379104]

31. Sikorski RS, Wang L, Markham KA, Rajagopalan PTR, Benkovic SJ, Kohen A. Tunneling and coupled motion in the E. coli dihydrofolate reductase catalysis. J Am Chem Soc 2004;126:47784779. [PubMed: 15080672]

32. Blakley RL. Crystalline dihydropteroylglutamic acid. Nature 1960;188:231-232.

33. Goodman MN, Masuoka LK, DeRopp JS, Jones AD. Use of deuterium-labeled glucose in evaluating the pathway of hepatic glycogen synthesis. Biochem Biophys Res Comm 1989;159:522-527. [PubMed: 2930527]

34. Jeong SS, Gready JE. A method of preparation and purification of (4R)-deuterated-reduced nicotinamide adenine dinucleotide phosphate. Anal Biochem 1994;221:273-277. [PubMed: 7810866]

35. Agrawal N, Kohen A. Microscale synthesis of 2-tritiated isopropanol and 4-R tritiated reduced nicotinamide adenine dinucleotide phosphate. Anal Biochem 2003;322:179-184. [PubMed: 14596825]

36. McCracken JA, Wang L, Kohen A. Synthesis of R and S tritiated reduced b-nicotinamide adenine dinucleotide 2' phosphate. Anal Biochem 2003;324:131-136. [PubMed: 14654055]

37. Markham KA, Sikorski RS, Kohen A. Synthesis and utility of ${ }^{14} \mathrm{C}$-labeled nicotinamide cofactors. Anal Biochem 2004;325:62-67. [PubMed: 14715285]

38. Markham KA, Sikorski RS, Kohen A. Purification, analysis, and preservation of reduced nicotinamide adenine dinucleotide 2'-phosphate. Anal Biochem 2003;322:26-32. [PubMed: 14705776]

39. Melander, L.; Saunders, WH. R. E. Krieger Pub; Malabar, FL: 1987.

40. Cleland, WW. (6) Enzyme mechanisms from isotope effects. In: Kohen, A.; Limbach, HH., editors. Isotope effects in chemistry and biology. Taylor \& Francis, CRC Press; Boca Raton, FL: p. 915-930.

41. Kohen A. Kinetic isotope effects as probes for hydrogen tunneling, coupled motion and dynamics contributions to enzyme catalysis. Prog React Kinet Mech 2003;28:119-156.

42. Northrop DB. Steady-state analysis of kinetic isotope effects in enzymatic reactions. Biochemistry 1975;14:2644-2651. [PubMed: 1148173]

43. Northrop, DB. Determining the absolute magnitude of hydrogen isotope effects. In: Cleland, WW.; O'Leary, MH.; Northrop, DB., editors. Isotope effects on enzyme-catalyzed reactions. University Park Press; Baltimore, MD: 1977. p. 122-152.

44. Northrop, DB. Intrinsic isotope effects in enzyme catalyzed reactions. In: Cook, PF., editor. Enzyme mechanism from isotope effects. CRC Press; Boca Raton, Fl: 1991. p. 181-202.

45. Streiwiester A, Jagow RH, Fahey RC, Suzuki F. Kinetic isotope effects in the acetolyses of deuterated cyclopentyl tosylates. J Am Chem Soc 1958;80:2326-2332.

46. Franciso WA, Knapp MJ, Blackburn NJ, Klinman JP. Hydrogen tunneling in peptidylglycinehydroxylating monooxygenase. J Am Chem Soc 2002;124:8194-8195. [PubMed: 12105892] 
47. Jonsson T, Edmondson DE, Klinman JP. Hydrogen tunneling in the flavoenzyme monoamine oxidase B. Biochemistry 1994;33

48. Kohen A, Cannio R, Bartolucci S, Klinman JP. Enzyme dynamics and hydrogen tunneling in a thermophilic alcohol dehydrogenase. Nature 1999;399

49. Bahnson BJ, Colby TD, Chin JK, Goldstein BM, Klinman JP. A link between protein structure and enzyme catalyzed hydrogen tunneling. Proc Natl Acad Sci USA 1997;94

50. Chin JK, Klinman JP. Probes of a role for remote binding interactions on hydrogen tunneling in the horse liver alcohol dehydrogenase reaction. Biochemistry 2000;39:1278-1284. [PubMed: 10684607]

51. Kiefer PM, Hynes JT. Kinetic isotope effects for adiabatic proton transfer reactions in a polar environment. J Phys Chem A 2003;107:9022-9039.

52. Kiefer, PM.; Hynes, JT. Interpretation of primary kinetic isotope effects for adiabatic and nonadiabatic proton transfer reactions in a polar environment. In: Kohen, A.; Limbach, HH., editors. Isotope effects in chemistry and biology. Taylor \& Francis Ltd., LLC CRC; Boca Raton, FL: 2006. p. 549-578.

53. Tautermann CS, Loferer MJ, Voegele AF, Liedla KR. Double hydrogen tunneling revisited: The breakdown of experimental tunneling criteria. J Chem Phys 2004;120:11650-11657. [PubMed: 15268199]

54. Smedarchina Z, Fernández-Ramos A, Siebrand W. Tunneling dynamics of double proton transfer in formic acid and benzoic acid dimers. J Chem Phys 2005;122:134309-134321. [PubMed: 15847467]

55. Smedarchina Z, Siebrand W. Generalized Swain-Schaad relations including tunneling and temperature dependence. Chem Phys Lett 2005;410:370-376.

56. Miller GP, Benkovic SJ. Deletion of a highly motional residue affects formation of the Michaelis complex for Escherichia coli dihydrofolate reductase. Biochemistry 1998;37:6327-6335. [PubMed: 9572847]

57. Kohen, A. Probes for hydrogen tunneling and coupled motion in enzymatic systems. In: Schowen, RL.; Klinman, JP.; Hynes, JT., editors. Biological aspects of hydrogen transfer. Wiley_VCH; Weinheim: 2006. in press

58. Cleland, WW. Multiple isotope effects in enzyme-catalyzed reactions. In: Cook, PF., editor. Eznyme Mechanism from Isotope Effects. CRC Press; Boca Raton, FL: 1991. p. 247-268.

59. Venkitakrishnan RP, Zaborowski E, McElheny D, Benkovic SJ, Dyson HJ, Wright PE.

Conformational changes in the active site loops of dihydrofolate reductase during the catalytic cycle. Biochemistry 2004;43:16046-16055. [PubMed: 15609999]

60. Hur S, Bruice TC. The near attack conformation approach to the study of the chorismate to prephenate reaction. Proc Nat Acad Sci USA 2003;100:12015-12020. [PubMed: 14523243]

61. Schowen RL. How an enzyme surmounts the activation energy barrier. Proc Nat Acad Sci USA 2003;100:11931-11932. [PubMed: 14530397]

62. Zhang X, Zhang X, Bruice TC. A definitive mechanism for chorismate mutase. Biochemistry. 2005ASAP Article

63. Maglia G, Javed MH, Allemann RK. Hydride transfer during catalysis by dihydrofolate reductase from Thermotoga maritima. Biochem J 2003;374:529-535. [PubMed: 12765545]

64. Bell, RP. The tunnel effect in chemistry. Chapman \& Hall; London \& New York: 1980.

65. Stern MJ, Weston RE Jr. Phenomenological manifestations of quantum-mechanical tunneling. III Effect on relative tritium-deuterium kinetic isotope effects. J Chem Phys 1974;60:2815-2821.

66. Schneider ME, JSM. Arrhenius preexponential factors for primary hydrogen kinetic isotope effects. J Am Chem Soc 1972;94

67. Kohen, A. Kinetic isotope effects as probes for hydrogen tunneling in enzyme catalysis. In: Kohen, A.; Limbach, HH., editors. Isotope effects in chemistry and biology. Taylor \& Francis, CRC Press; Boca Raton, FL: 2006. p. 743-764.

68. Kohen A, Klinman JP. Hydrogen tunneling in biology. Chem Biol 1999;6:R191-R198. [PubMed: 10381408]

69. Kohen A, Klinman JP. Enzyme catalysis: Beyond classical paradigms. Acc Chem Res 1998;31:397404.

70. Marcus RA. Electron, proton and related transfers. Faraday Discuss Chem Soc 1982;74:7-15. 
71. Marcus RA, Sutin N. Electron transfer in chemistry and biology. Biochem Biophys Acta 1985;811:265-322.

72. Kreevoy, MM.; Truhlar, DG. Transition State Theory. In: Bernasconi, CF., editor. Investigation of rates and mechanisms of reactions. John Wiley and Sons; New York: 1986. p. 13-95.

73. Kim Y, Truhlar DG, Kreevoy MM. An experimentally based family of potential surfaces for hydride transfer between NAD ${ }^{+}$Analogues. J Am Chem Soc 1991;113:7837-7847.

74. Knapp MJ, Klinman JP. Environmentally coupled hydrogen tunneling - Linking catalysis to dynamics. Eur J Biochem 2002;269:3113-3121. [PubMed: 12084051]

75. Knapp MJ, Rickert K, Klinman JP. Temperature-dependent isotope effects in soybean liposygenase-1: Correlating hydrogen tunneling with protein dynamics. J Am Chem Soc 2002;124:3865-3874. [PubMed: 11942823]

76. Borgis DC, Hynes JT. Dynamical theory of proton tunneling transfer rates in solution: general formulation. Chem Phys 1993;170:315-346.

77. Borgis DC, Hynes JT. Curve crossing formulation for proton transfer reactions in solution. J Phys Chem 1996;100:1118-11128.

78. Borgis DC, Lee SY, Hynes JT. A dynamical theory of nonadiabatic proton and hydrogen atom transfer reaction rates in solution. Chem Phys Lett 1989;162

79. Sutcliffe MJ, Scrutton NS. A new conceptual framework for enzyme catalysis. Hydrogen tunning coupled to enzyme dynamics in flavoprotein and quinoprotein enzymes. Eur J Biochem 2002;269:3096-3102. [PubMed: 12084049]

80. Antoniou D, Caratzoulas S, Kalyanaraman C, Mincer JS, Schwartz SD. Barrier passage and protein dynamics in enzymatically catalyzed reactions. Eur J Biochem 2002;269:3103-3112. [PubMed: 12084050]

81. Schenter GK, Garrett BC, Truhlar DG. The role of collective solvent coordinates and nonequilibrium solvation in charge-transfer reactions. J Phys Chem B 2001;105:9672-9685.

82. Kuznetsov AM, Ulstrup J. Proton and hydrogen atom tunneling in hydrolytic and redox enzyme catalysis. Can J Chem 1999;77:1085-1096.

83. Garcia-Viloca M, Gao J, Karplus M, Truhlar DG. How enzymes work: Analysis by modern rate theory and computer simulations. Science 2003;303:186-195. [PubMed: 14716003]

84. Shurki A, Warshel A. Structure/function correlations of enzymes using MM, QM/MM and related approaches; methods, concepts, pitfalls and current progress. Adv Prot Chem 2003;66:249-313.

85. Hatcher E, Soudackov AV, Hammes-Schiffer S. Proton-coupled electron transfer in soybean lipoxygenase. J Am Chem Soc 2004;126:5763-5775. [PubMed: 15125669]

86. Villa J, Warshel A. Energetics and dynamics of enzymatic reactions. J Phys Chem B 2001;105:78877907.

87. Bigeleisen J. The rule of the geometric mean. J Chem Phys 1955;23:2264-2267.

88. Huskey WP, Schowen RL. Reaction-coordinate tunneling in hydride transfer reactions. J Am Chem Soc 1983;105:5704-5706.

89. Huskey WP. Origin of apparent Swain-Schaad deviations in criteria for tunneling. J Phys Org Chem 1991;4:361-366.

90. Lin S, Saunders WH. Tunneling in elimination reactions - structural effects on the secondary betatritium isotope effect. J Am Chem Soc 1994;116:6107-6110.

91. Pu J, Ma S, Garcia-Viloca M, Gao J, Truhlar DJ, Kohen A. Nonperfect synchronization of reaction center rehybridization in the transition state of the hydride transfer catalyzed by dihydrofolate reductase. J Am Chem Soc. 2005Accepted for publication

92. Cha Y, Murray CJ, Klinman JP. Hydrogen tunneling in enzyme reactions. Science 1989;243:13251330. [PubMed: 2646716] 


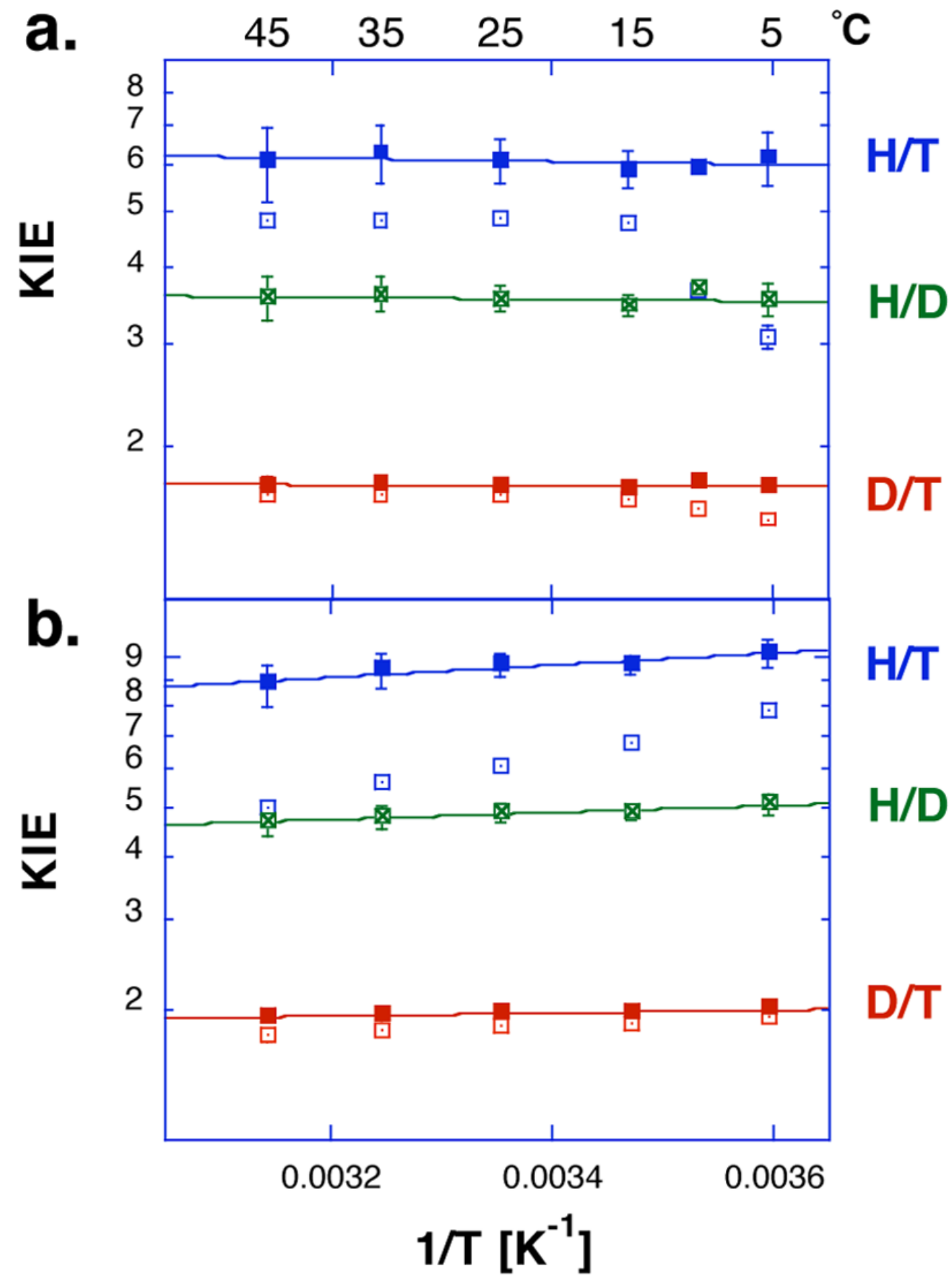

Figure 1.

Arrhenius plot of observed (open structures) and intrinsic (close structures) $1^{\circ} \mathrm{KIEs}$ for the wild type ecDHFR (Panel a. From Ref (31)) G121V-ecDHFR (Panel b. From Tables 1 and 2 in the Supplementary Information to this paper). The lines represent the non-linear regression to Equation 2. 


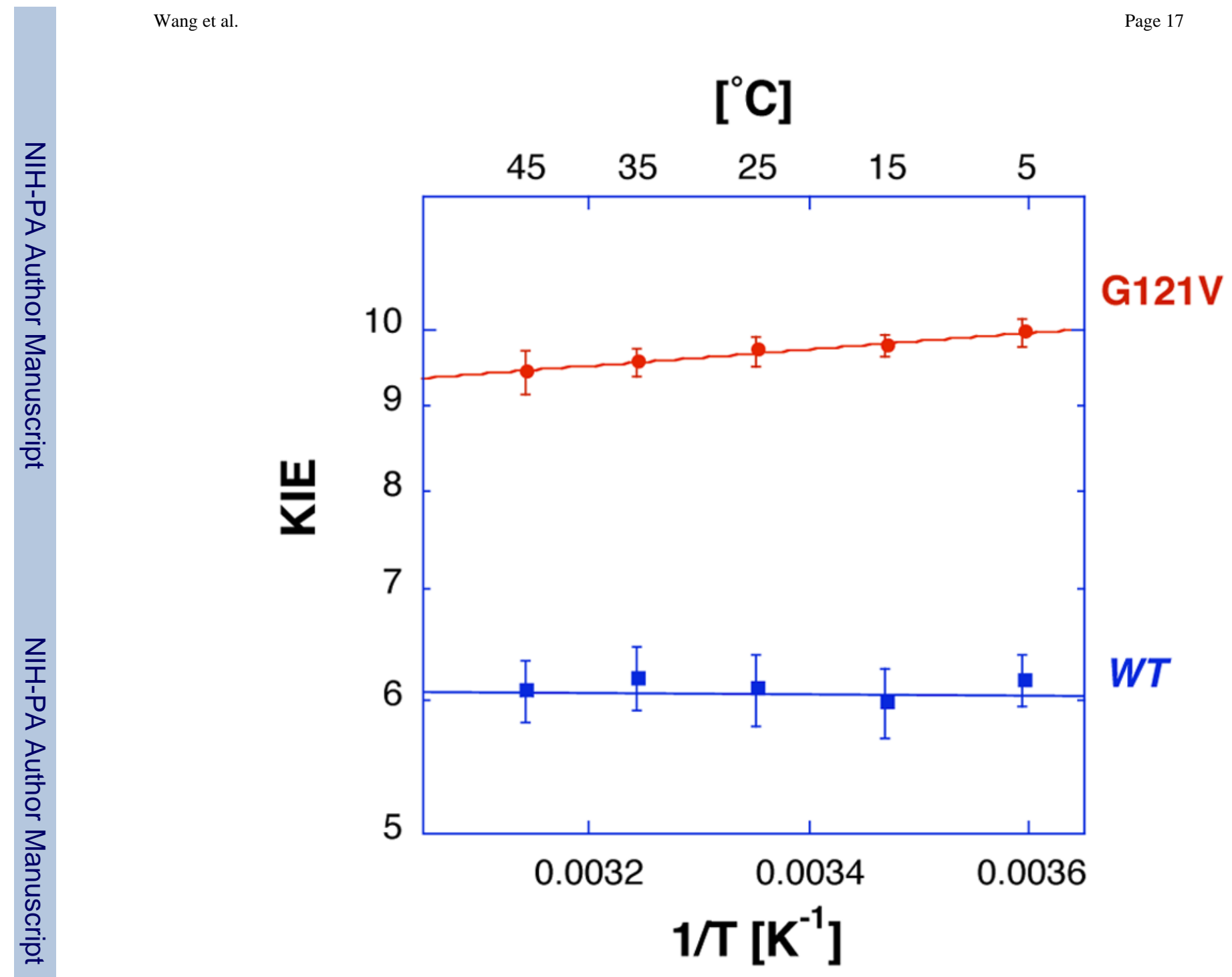

Figure 2.

Arrhenius plot of intrinsic H/T KIEs for the wild type (blue) and G121V (red) ecDHFR (same as the blue points and lines in both panels of Figure 1). 


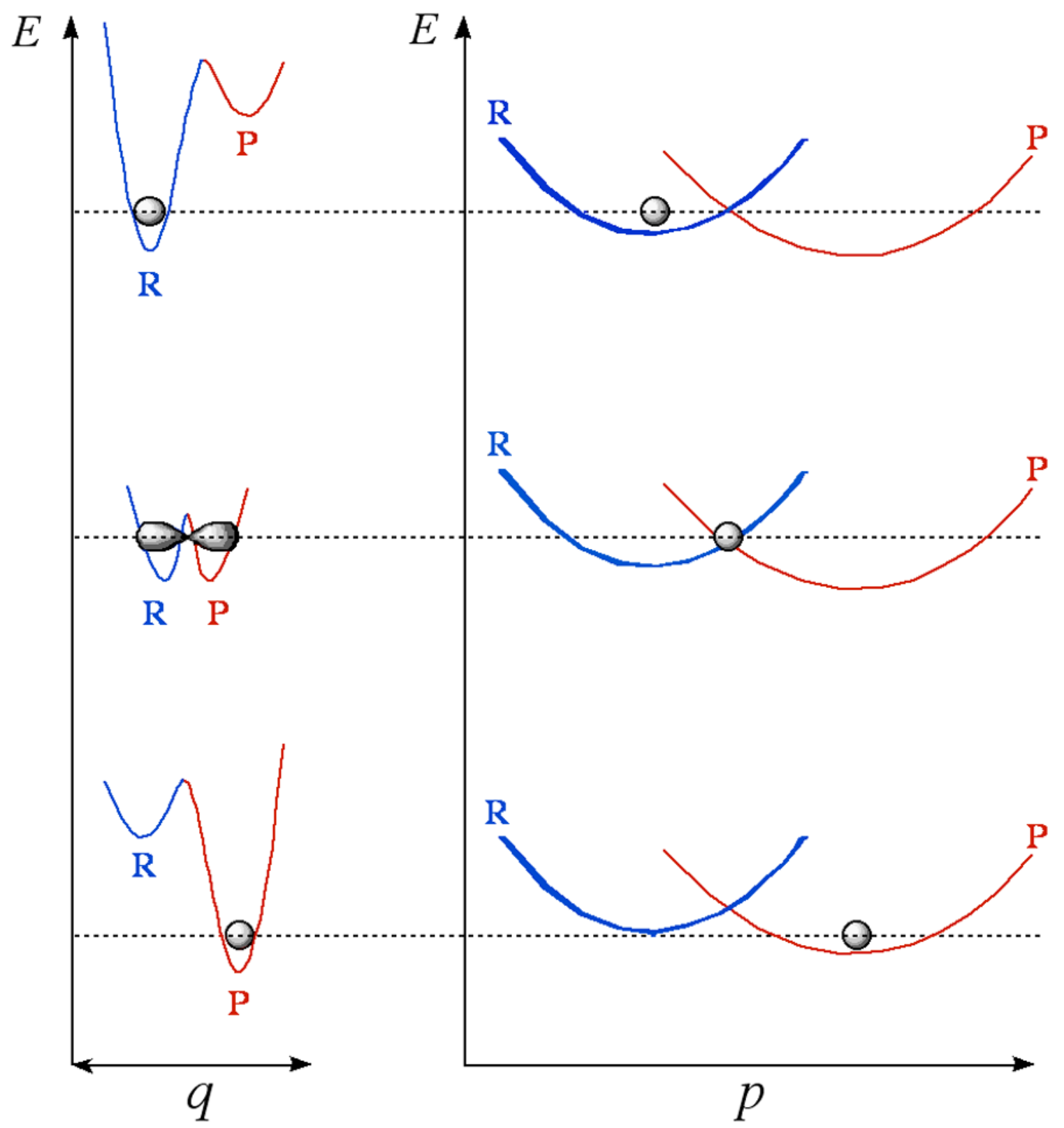

Figure 3.

Illustration of "Marcus-like" models: energy surface of environmentally coupled hydrogen tunneling. Two orthogonal coordinates are presented: $\boldsymbol{p}$, the environmental energy parabolas for the reactant state $(R)$ and the product state $(P)$; and $\boldsymbol{q}$, the H-transfer potential surface at each $\boldsymbol{p}$ configuration. The gray shapes represent the populated states (e.g., the location of the particle). Thermal fluctuations of the distance between donor and acceptor along the $\boldsymbol{q}$ coordinate (denoted "gating" by Knapp and Klinman (74)) leads to the temperature dependency of the KIE. 
Table 1

Rates and isotope effects on Arrhenius factors.

\begin{tabular}{|c|c|c|c|}
\hline$E c$ DHFR: ${ }^{a}$ & Wild Type $^{b}$ & G121V & \\
\hline Rate $^{c}\left[\mathrm{~s}^{-1}\right]$ & $228 \pm 8$ & $1.4 \pm 0.2$ & S.C. $A_{\mathrm{l}} / \boldsymbol{A}_{\mathrm{h}}{ }^{d}$ \\
\hline $\begin{array}{l}A_{\mathrm{H}} / A_{\mathrm{T}} \\
A_{\mathrm{H}} / A_{\mathrm{D}} \\
A_{\mathrm{D}} / A_{\mathrm{T}}\end{array}$ & $\begin{array}{l}7.0 \pm 1.5 \\
3.5 \pm 0.5 \\
1.70 \pm 0.14\end{array}$ & $\begin{array}{l}6.6 \pm 1.3 \\
3.7 \pm 0.5 \\
1.8 \pm 0.1\end{array}$ & $\begin{array}{l}0.5-1.6 \\
0.6-1.4 \\
0.9-1.2\end{array}$ \\
\hline $\begin{array}{l}\Delta E \mathbf{a}_{\mathrm{H}-\mathrm{T}} \\
\Delta E \mathbf{a}_{\mathrm{H}-\mathrm{D}} \\
\Delta E \mathbf{a}_{\mathrm{D}-\mathrm{T}}\end{array}$ & $\begin{array}{l}-0.1 \pm 0.4 \\
-0.07 \pm 0.3 \\
-0.03 \pm 0.1\end{array}$ & $\begin{array}{l}0.22 \pm 0.12 \\
0.16 \pm 0.08 \\
0.07 \pm 0.03\end{array}$ & \\
\hline $\begin{array}{l}\boldsymbol{\Delta} \boldsymbol{G}^{\dagger}{ }_{25}^{\circ} \mathrm{C} \\
\Delta \boldsymbol{H}^{\dagger}{ }^{\circ} \\
\mathbf{T} \boldsymbol{\Delta} \boldsymbol{S}^{\dagger}{ }_{25}{ }^{\circ} \mathrm{C}\end{array}$ & $\begin{array}{l}14.3 \pm 0.5 \\
3.1 \pm 0.2 \\
-11.2 \pm 0.5\end{array}$ & $\begin{array}{l}17.3 \pm 0.5 \\
2.6 \pm 0.3 \\
-14.7 \pm 0.6\end{array}$ & \\
\hline
\end{tabular}

${ }^{a}$ All energy units are in $\mathrm{kcal} / \mathrm{mol}$

${ }^{b}$ From Ref. (31).

${ }^{c}$ Pre-steady state rates at $\mathrm{pH}=7$ from Refs (11) and (30).

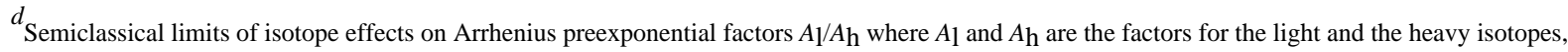
respectively $(39,41,57,64-67)$. 